\title{
RESEARCH METHODS AND TECHNIQUES IN NEW MANAGEMENT TRENDS: RESEARCH RESULTS
}

\author{
Henryk Dźwigoł
}

\begin{abstract}
Findings from domestic and foreign literature analyses on the research methods and techniques applied in the management sciences confirmed the necessity to elaborate a certain procedure of selecting proper research methods, with consideration given to new management trends. With reference to the foregoing, the article presented qualitative studies (interviews, experts' opinions) and quantitative ones (surveys) in order to diagnose the problem in a proper way by providing answers to five research hypotheses. As a result of the research effort, the anticipated goal of the article was achieved, i.e. the readers were presented with an elaborated procedure (Dźwigot, 2018) of selecting the methods and techniques for the sake of the management-related research process, and with essential components of the research process used for designing the procedure in question. Since the research hypotheses were positively assessed, the author was able to present recommendations as to putting the procedures into practice, which were supported by a dedicated online tool. What is more, the achieved goal allowed not only to determine the application rate of the particular methods and techniques, or their combined versions, but also to identify certain rules as to recognising the research process in the present context and in terms of other variables, since the latter may influence whether the selected methods and techniques, related to the research subject in the context of management sciences, are essential. All foregoing steps were aimed at enhancing the reliability, quality and level of the research studies being carried out. Furthermore, it was recommended to perform further research studies aimed at verifying the adopted model and procedure of selecting research methods and techniques in the management sciences, especially in the practical context.
\end{abstract}

Keywords: method, research process, triangulation

JEL Classification: B40, C10, C00

\section{Author(s):}

\section{Henryk Dźwigoł}

Silesian University of Technology, 26 Roosevelta Street, Zabrze, Poland, 41-800

E-mail: henryk.dzwigol@polsl.pl

https://orcid.org/0000-0002-2005-0078

Citation: Dźwigoł, H. (2019). Research methods and techniques in new management trends: research results. Virtual Economics, 2(1), 31-48. https://doi.org/10.34021/ve.2019.02.01(2) 


\section{Introduction}

In today's science and economy ( $21^{\text {st }}$ century) we have been witnessing development of management sciences, aiming at making use of non-complicated and comprehensive methods in order to ponder on each aspect of the same problem (Coghlan \& Shani, 2016; Collins, 2010; Harrington \& Voehl, 2016). Managing of a contemporary company necessitates not only to enhance its effectiveness, but also improve the company's value (Gerring, 2017; Mooi et al., 2018). Due to the changes occurring in the environment of the company, it has been necessary to elaborate new rules, principles and ways for the company operation, as well as new management systems (O'Leary \& Hunt, 2016; Petrova, 2018). With reference to that, the $21^{\text {st }}$ century management sciences had to adopt a new paradigm; it was based on the ability to cope with continuous changes. It is said that a change is the only permanent phenomenon in the modern economic world (Singleton \& Straits, 2017; Sloan \& Quan-Haase, 2017).

In the literature, one may additionally identify some statements that have confirmed poor methodology-related character of management sciences, as well as have emphasised the necessity to effectively achieve knowledge, methods and techniques borrowed from other sciences' research tools (Labarca, 2017; O'Leary, 2017; Quinton \& Reynolds, 2018; Robbins, 2009; Thomas, 2017). It is always underlined that separating and developing the methods specific only for management sciences are not needed; on the other hand, it is necessary to transdisciplinarilly integrate overly specialised sciences.

Nonetheless, the conclusions on poor methodological state of management sciences turn out to be far-fetched. It needs to be emphasised that one is able to identify, among various methods employed in the management sciences, both methods typical of management as well as methods borrowed from other scientific disciplines. The borrowed methods relate, in most cases, to familiarising oneself with the organisation and its management, whereas the researchers' own methods are aimed at developing the organisation itself and a system of its management. Among basic methods of recognising the organisation and its management, one can distinguish:

- Survey methods (derived from social sciences),

- Observation methods (coming from natural sciences),

- Ethnological methods (coming from anthropology),

- Pseudo-experimental methods (coming from natural and social sciences),

- Documentation-related methods (coming from social and historical sciences).

It often happens that the application of management methods, as well as classifying the management as one of the branches of science are subject of critical analyses. It is, more often than not, caused by appearance of new management methods that happen to be quickly rendered obsolete and that are being used only because there is a trend of employing them. What is more, new methods are very often sold to companies in the form of marketing products, whereas some researchers express serious doubts as to their effective application. 
It needs to be stated that, in spite of critical views, both management sciences and their methods and methodology result in the improved effectiveness and competitiveness of companies. However, it needs to be mentioned that management methods are not and cannot be of universal character. The methods must be adjusted as the time goes by, as the company changes over the years (Gerring, 2017; Mooi et al., 2018; Quian, 2018).

In modern management science, research and analyses focus mainly on the quality of the research process. The latter influences the accuracy and quality of the decisions taken.

The difference between the modern and traditional approaches is significant. In the traditional approach to the management (in particular with reference to research processes) the main stress is put on finding answers to the following questions:

- Which elements - of an organisation, process, etc. are not working properly?

- Which elements should be regarded as inappropriate?

- What are the reasons for that?

The traditional approach does not always allow to achieve satisfactory results; what is more, it does not always result in improving the existing situation.

Within the scope of the contemporary approach, various types of principles, procedures or tools are elaborated. They allow, contrary to the traditional approach, to enhance the knowledge of the existing problem situation (Ares \& Varela, 2018a, 2018b; Quian, 2018). To this end, one may adopt the following perspective - the Positive Organizational Scholarship (SOP). Upon its implementation, one needs to pose a basic question, i.e.: Why are some employees so ineffective? Then, the following questions are asked:

- Why is it so?

- What are the reasons for such a phenomenon?

As a result of the applied SOP perspective, one will find an answer to the following question - what needs to be done to achieve the desired state, i.e. what needs to be done to be good at something and how to achieve perfection.

In modern management sciences, the methodological fundamentalism was rejected, which stringently defined the scientific character of a method, evoking neo-positivist models in natural sciences (Hempoliński, 1992). In the literature on management sciences, the necessity of employing diverse research methods to study and develop organisations in research processes has been highlighted many times.

In the literature on management sciences, the necessity to apply numerous self-verifying and self-correcting methods has been highlighted many a time (Coghlan \& Shani, 2016; Collins, 2010; Denzin, 1970; Harrington \& Voehl, 2016).

Furthermore, there occurred a phenomenon of methodological pluralism. It has advocated that in order to solve a research problem, one should be ready to apply research methods derived from various disciplines and theoretical approaches. It means that the multitude of 
ways in which the world is perceived shall be combined with multitude and diversity of ways, methods, evaluation techniques, and attempts to transform the world' (Dźwigot, 2018). However, it very often causes anarchism and methodological eclecticism. With reference to the foregoing, in order to achieve reliable research results, it is necessary to analyse in details the research problem, and consequently select such research methods that would facilitate the avoidance of the above-mentioned phenomena (Boland et al., 2017).

\section{Research scope and methodology}

Diversity consists in both similarities and differences between people, associated with their age, culture, physical abilities, physical appearance, disability, race, nationality, religion, gender. Conclusions derived from an ongoing analysis of national and foreign literature dealing with methodology of conducting a research process showed a deficit in empiric approaches to the quality of research processes. With reference to the foregoing, the following research hypotheses were posed in the article:

$\mathrm{H} 1$. Upon determining the research problem, it is necessary to analyse selected qualitative and quantitative methods in order to make a preliminary selection.

$\mathrm{H} 2$. Verification of elaborated methods, models or procedures is a prerequisite to combine management science and practice.

H3. Methodological triangulation supports research processes.

H4. Combining qualitative and quantitative methods in management-related research processes enhances the quality and reliability of research findings.

H5. Expert groups assessment should be regarded as a basic method of evaluating trends of the carried-out research.

In order to find answers to the posed research questions, the research study involved an anonymous survey questionnaire and a structured interview ${ }^{1}$ distributed in paper form at conferences from the area of management sciences, and electronically, on the basis of an email database, elaborated earlier. The research study was carried out from October 2016 to April 2018.

The questionnaire consisted of three parts. The first part contained questions about the importance of approaches, processes, methods and techniques in a research process within the scope of management sciences (5 questions). The second part consisted of questions related to the problem of the improvement of a research process (33 questions). The third part contained demographics (3 questions). The structure of the questionnaire in the research part involved both open, rank questions, and questions based on the 5-point Likert scale. Within the scope of the latter, the respondents were obliged to classify a particular answer as: strongly agree (5), agree (4), neither agree nor disagree (3), disagree (2), strongly disagree (1), with reference to each of the proposed assumptions.

1 The research study was designed for academic staff members, within the scope of the management science discipline. 
On the other hand, the interview survey involved an introduction - in the form of a letter of intent - two open questions and final information containing thank-you notes and postal addresses under which answers were to be sent. The respondents were asked the following questions: 'Does combining qualitative and quantitative methods in management-related research processes enhance the quality and reliability of research findings?' and 'Which qualitative or quantitative methods enhance the new management paradigm in the context of science and business practice?'

Quantitative research (survey questionnaires) covered theoreticians of management sciences, being a target group. The group consisted of:

- 272 foreign universities having faculties and/or units dealing with management sciences,

- 21,024 foreign academic staff connected to the management sciences,

- 93 national universities having faculties and/or units dealing with management sciences,

- 2,307 national academic staff connected to the management sciences,

- 52 foreign companies,

- 183 national companies.

The size of a research sample, necessary to determine representative character of the research, was determined on the basis of the following assumptions:

- the $p$ fraction ratio was set to $50 \%^{2}$,

- the amount of an error related to the fraction ratio was set to $5 \%$,

- statistical significance $\alpha=0.05$.

On the basis of the above-mentioned assumptions, the requested sample size formula is simplified, and looks as follows (Kukuła, 2007):

$$
n_{p}=\frac{u_{\alpha}^{2} * p(1-p)}{b_{p}^{2}}=\frac{u_{\alpha}^{2}}{4 b_{p}^{2}}=\frac{1.96^{2}}{4 * 0.05^{2}}=384.16
$$

where:

$\mathrm{n}_{\mathrm{p}}$ - requested sample size,

$\mathrm{u}_{\alpha}$ - amount of cumulative normal distribution derived from statistical tables,

$\mathrm{p}$ - fraction ratio,

$b$ - the size of the fraction ratio error.

As a result of the research effort, 401 representatives of management science theorists were surveyed, thus the condition determining the representative character of the research sample was met.

2 Should it be difficult to assess the volume of the population, such an approach shall be permissible. 
In the surveyed group of scientists, Polish universities amounted to $32 \%$, whereas foreign universities accounted for $33 \%$. As to the remaining part of the research group (35\%), no academic unit was indicated. The most common areas of sciences in which the researchers were involved were, among others: strategic management, company management, knowledge and innovation management, as well as methodics of the research on organisations.

\section{Selected research results - verification of research hypotheses}

$\mathrm{H}_{1}$ - Having developed a research question, it is necessary to analyse selected quantitative and qualitative methods in order to make a preliminary selection.

$\mathrm{H}_{\mathrm{a} 1}$ - Having developed a research question, it is not necessary to analyse selected quantitative and qualitative methods in order to make a preliminary selection.

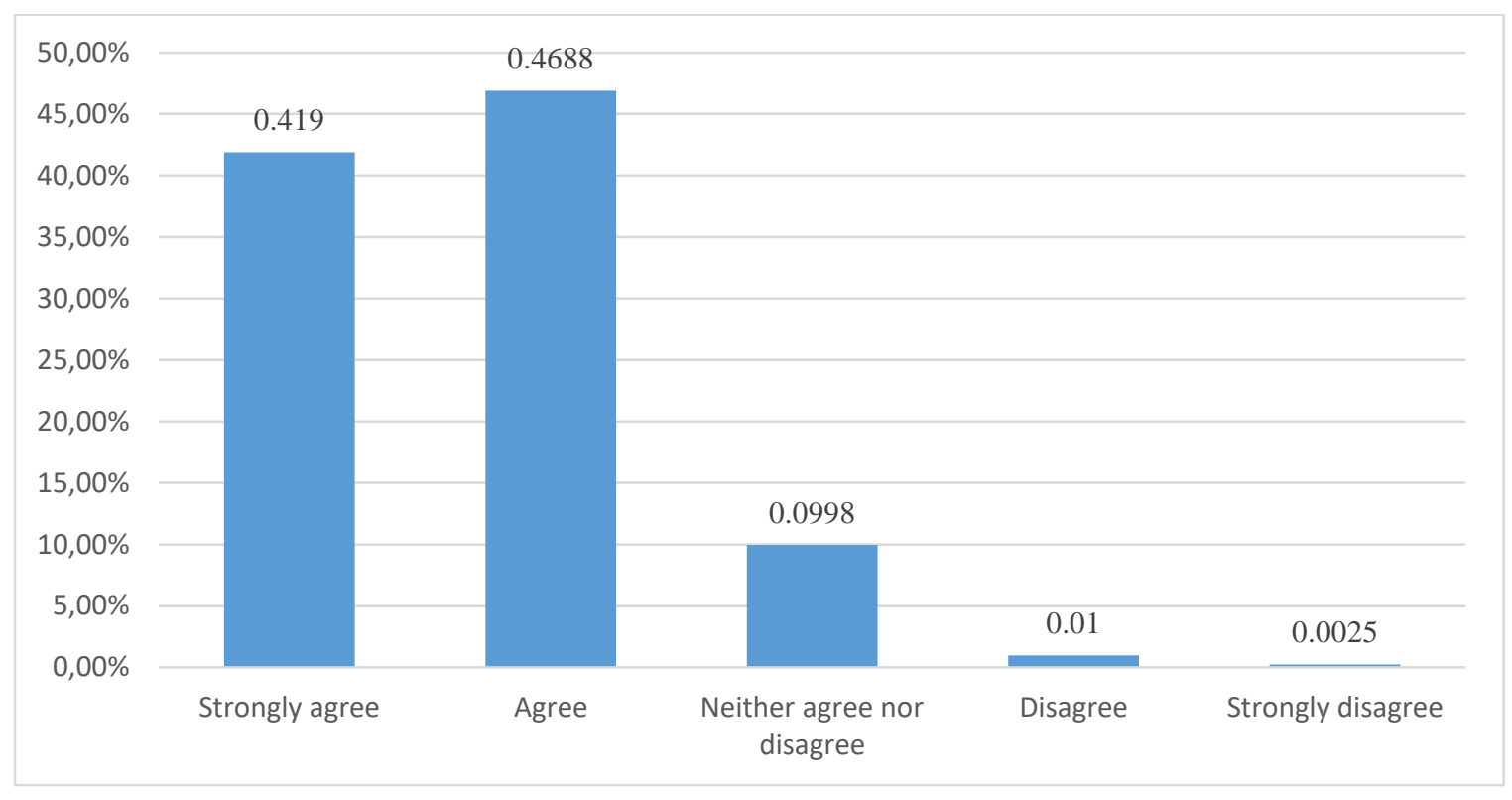

Figure 1. Necessity to analyse selected quantitative and qualitative methods in order to perform their preliminary selection upon the formulation of the research problem - research results

Source: the author's own work.

While analysing the achieved results, one may undoubtedly state that upon formulation of the research problem, it is necessary to analyse the chosen quantitative and qualitative methods in order to pursue their preliminary selection, which is underlined by $88.78 \%$ of the respondents. One may find arguments to support the above-mentioned thesis in the source literature, where it is claimed, more often than not, that in order to diagnose the research problem comprehensibly and thoroughly, it is necessary to apply diverse research methods, providing an exhaustive answer to the posed question. 
Furthermore, the very development of heterogenous cognitive methods, modelling or organisation management has an impact on the necessity to adopt an open-minded approach, allowing or even encouraging to combine numerous approaches and methods. Practical aspect of the devised methods, procedures or models were verified in order to make the research more reliable. Moreover, before undertaking research studies, it is necessary to analyse the chosen methods against the character of the carried-out research (Labarca, 2017; O'Leary, 2017; Quinton \& Reynolds, 2018; Robbins, 2009; Thomas, 2017).

$\mathrm{H}_{2}$ - Verification of elaborated methods, models or procedures is a prerequisite that allows to combine practical and theoretical aspects of management sciences.

$\mathrm{H}_{\mathrm{a} 2}$ - Verification of elaborated methods, models or procedures is not necessary to combine practical and theoretical aspects of management sciences.

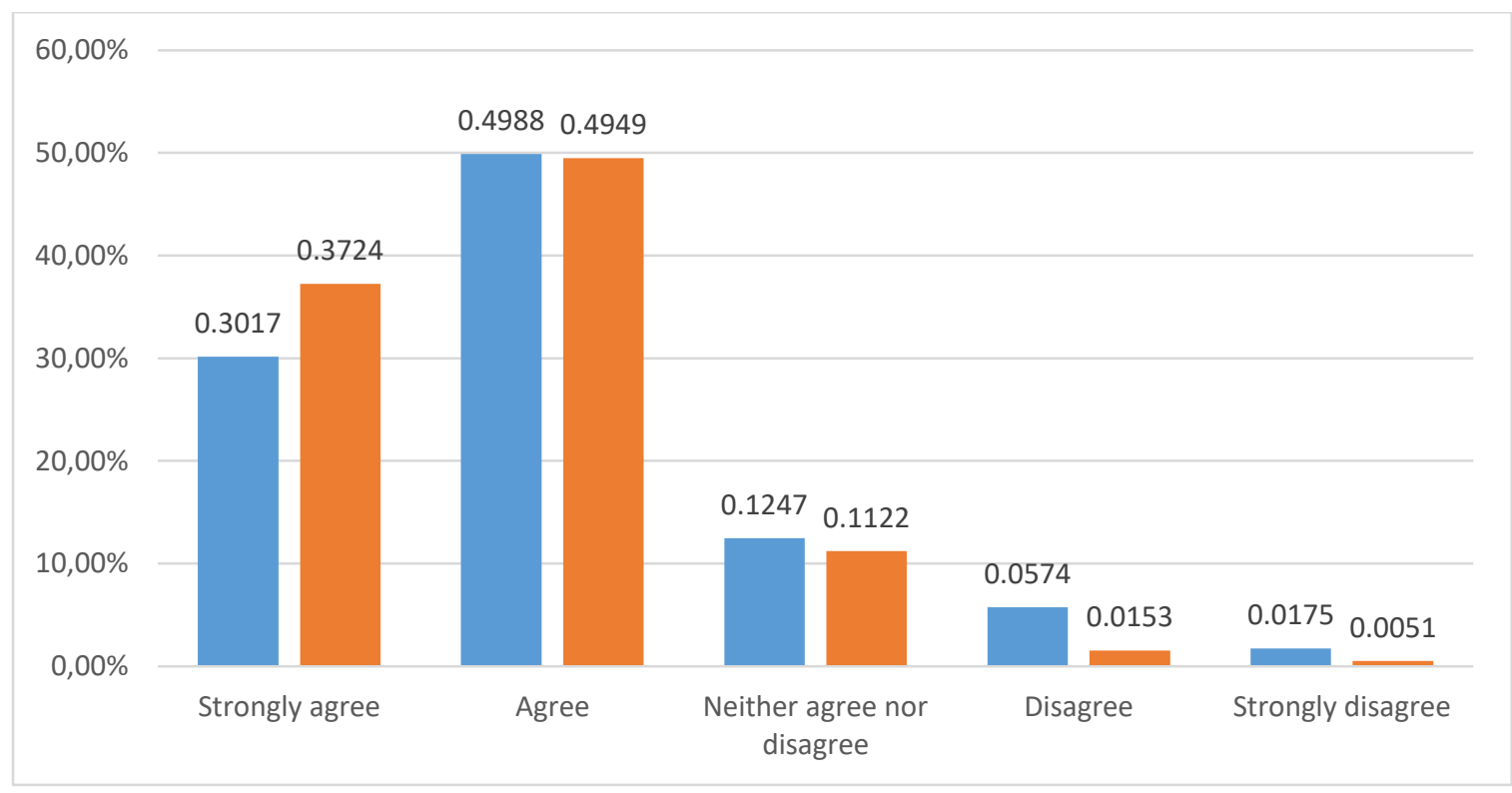

Figure 2. Verification of elaborated methods, models or procedures is a prerequisite that allows to combine practical and theoretical aspects of management sciences - research results

Source: the author's own work.

The statistical analysis of achieved data unequivocally states that most respondents, i.e. $80.05 \%$ hold the opinion that it is a prerequisite allowing to combine practical and theoretical aspects of management sciences. The view is shared by $86.73 \%$ of management practitioners, which allows to confirm the said hypothesis.

$\mathrm{H}_{3}$ - Methodological triangulation supports research processes in management sciences.

$\mathrm{H}_{\mathrm{a} 3}$ - Methodological triangulation does not support research processes in management sciences. 


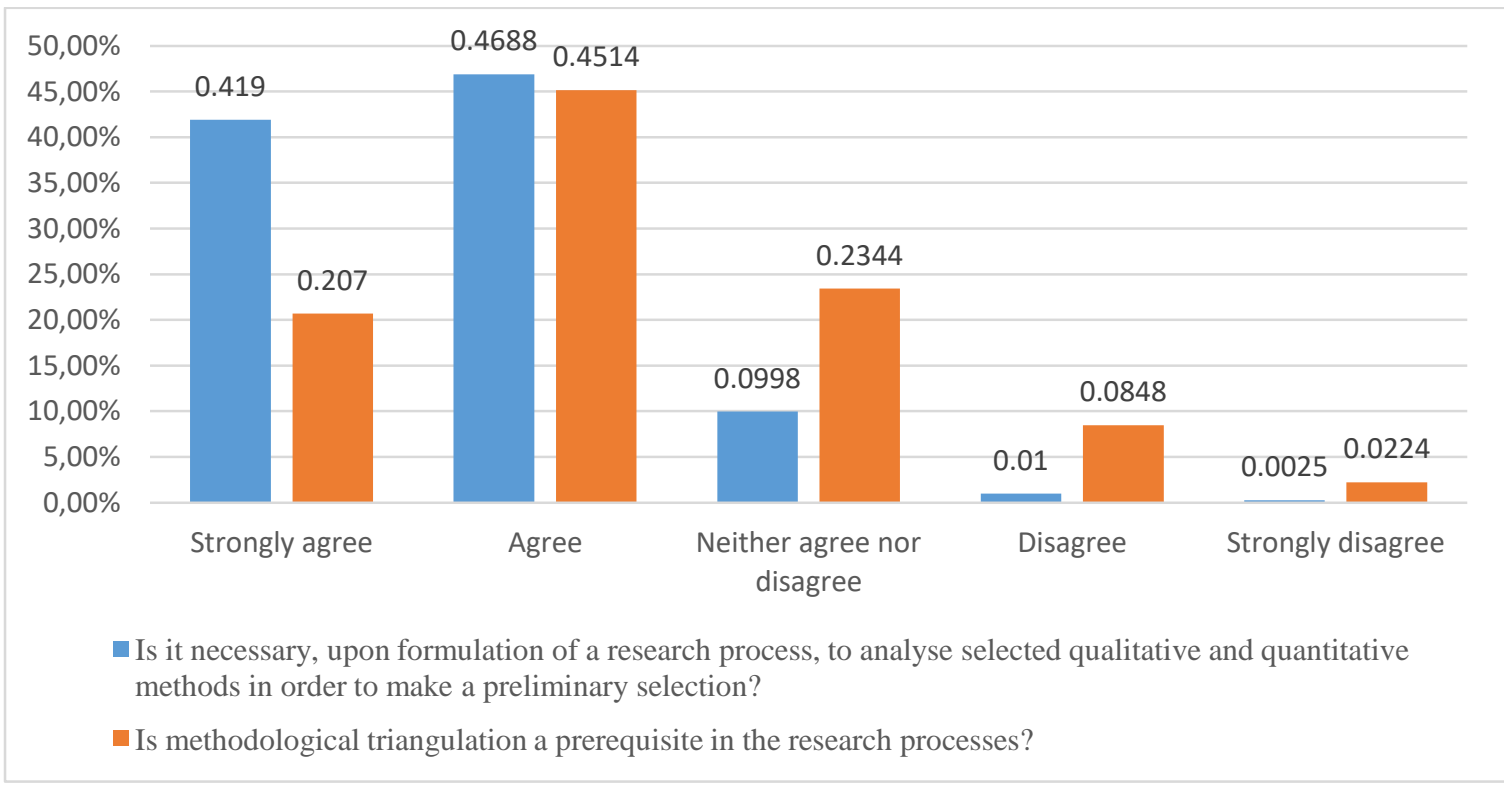

Figure 3. Methodological triangulation versus research process - research conclusions Source: the author's own work.

In the sample in question, $82.29 \%$ of the respondents claim that methodological triangulation supports the research process. What is more, $69.08 \%$ of the surveyed researchers emphasise that the triangulation is a precondition in the management sciences. The achieved findings were also confirmed by an extensive literature study on the research methodology. It was stated in the said literature that the application of numerous differentiated methods in the research process allows to adopt a complex approach to the research problem, while providing it with a broader image.

Methodological triangulation is the answer to the problem of selecting just one adequate method, since the problem might undoubtedly distort the research findings. In the beginning, the researcher should assume that selecting a few good methods will result in more comprehensive information and will allow to find out more about the phenomenon, instead of focusing on selecting the best method.

$\mathrm{H}_{4}$ - Combining qualitative and quantitative methods in the management-related research processes enhances the quality and reliability of the research findings.

$\mathrm{H}_{\mathrm{a} 4}$ - Combining qualitative and quantitative methods in the management-related research processes does not enhance the quality and reliability of the research findings.

According to the interviewed experts, combining quantitative and qualitative methods in the management-related research processes shall considerably affect the quality of the process itself and reliability of the research findings. What is more, the experts state that it is not always easy, in practical research studies, to make a clear distinction between quantitative and qualitative methods, where specific conditions should be met, e.g. an order of applying particular methods or objectivism as to the research findings. Furthermore, K. Pająk (Pająk, 
2010, pp. 185-215), Professor, holds the opinion that qualitative research in the management sciences focuses on a comprehensive analysis of a given phenomenon. The main emphasis is put on understanding the analysed problem, in a better and more precise way, with the use of special research methods. The qualitative research, as opposed to the quantitative one, is not structured to a considerable extent, due to the lack of quantitative approach, as the statistical reasoning is not applied very often. In an ideal methodological situation, if a researcher is willing to study or discover something, verify a set hypothesis or research question, then the quantitative and qualitative research should complement each other.

Functions and usefulness of both kinds of methods and their combination are undoubtedly diverse, among other things due to the research subject and research goals, as well as the phase of the research process. Nonetheless, should the researchers' interest evolve around discovering and/or recognising (combined with interpreting) cause-and-effect relations, or mechanisms in which functions and processes are carried out, its underlying factors and further consequences, as well as subsequent formulation of research hypotheses, then the quantitative methods should be obligatorily supported by (additional) qualitative methods.

$\mathrm{H}_{5}$ - Expert groups assessment should be regarded as a basic method of evaluating trends of the carried-out research.

$\mathrm{H}_{\mathrm{a} 5}$ - Expert groups assessment should not be regarded as a basic method of evaluating trends of the carried-out research.

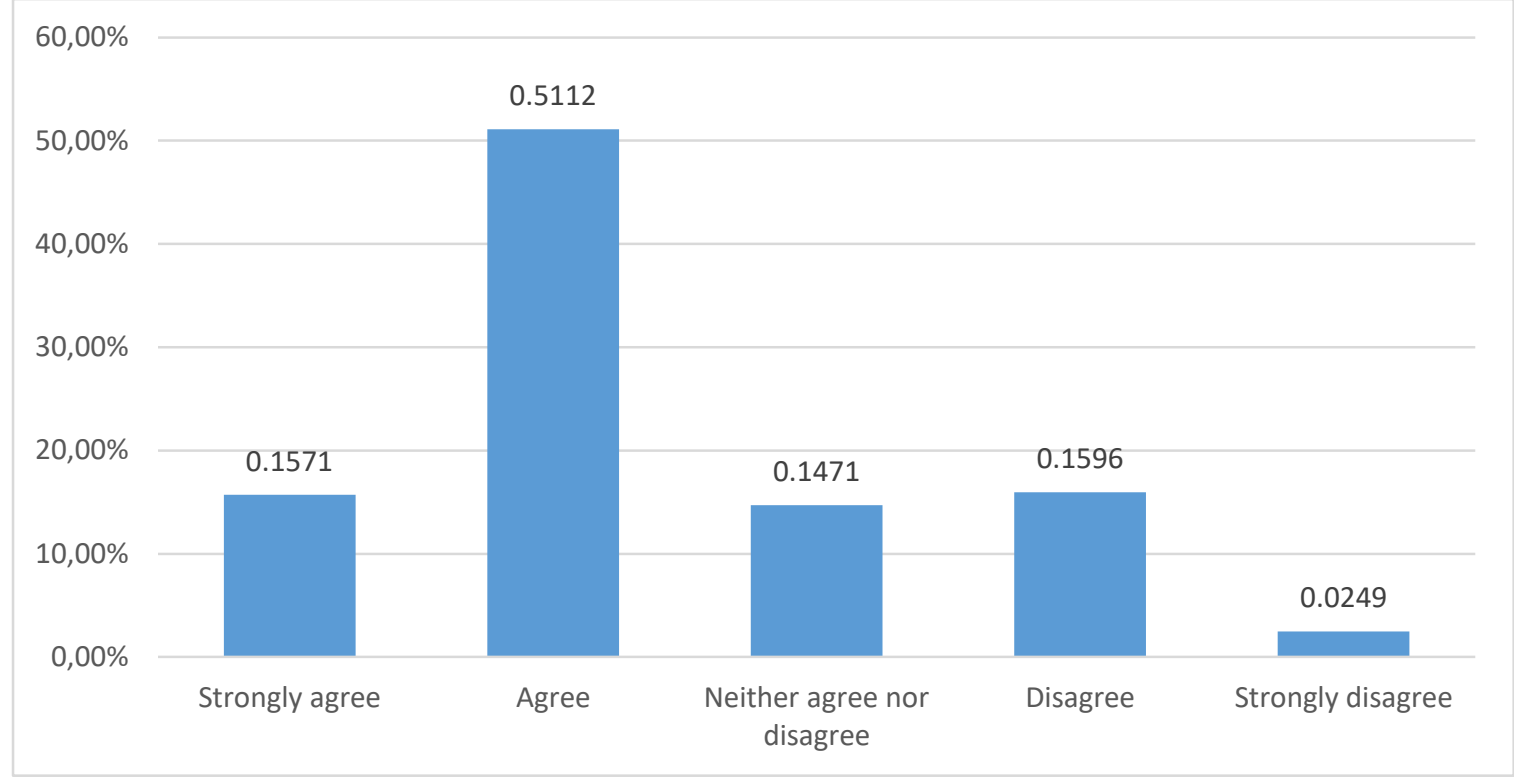

Figure 4. Expert groups assessment should be regarded as a basic method of evaluating trends of the carried-out research - research results

Source: the author's own work. 
A considerable number of the researchers (66.83\%) believe that the expert group assessment should be regarded as a basic method of evaluating trends of the carried-out research, which confirms the hypothesis.

\section{Elaborating a procedure of selecting methods and techniques for management-related research process - online tool}

The principal aim of the article was to elaborate a model of selecting methods and procedures affecting the course of the research process for the sake of practical and theoretical aspects of management.

In the beginning, the model and procedure were developed on the basis of methodological assumptions characterising models, processes or methods of carrying out research processes within the scope of management sciences. Findings from domestic and foreign literature (Dźwigoł, 2018; Dźwigoł \& Dźwigoł-Barosz, 2018) analyses have unequivocally confirmed that already at the phase of defining the research problems it is difficult to select one method allowing to diagnose the problem comprehensively and thoroughly. It is thus necessary to employ various research methods that would give a complex answer to the posed problem. The very development of heterogenous cognitive methods, modelling or organisation management has an impact on the necessity to adopt an open-minded approach, allowing or even encouraging to combine numerous approaches and methods (Quian, 2018; Quinton \& Reynolds, 2018). In order to develop a universal procedure, the experts defined, within the course of consultations, five elements to be taken into consideration upon selecting the methods and techniques suitable for the research process, including theses, hypotheses or research questions:

- selecting a research subject - defining what object lies in the interest of a given researcher;

- determining the character of the carried-out research - the researcher should precisely define a type, character and kind of the carried-out research;

- determining the research transparency - literature-based inference and practical experience show that the aim of the research may be presented in various ways depending on its defined character. In the given case, the researcher should state what method he/she is going to use to present a predefined aim of the carried-out research;

- selecting a way in which the research study is carried out - conclusions reached on the basis of methods and techniques described in the source literature prove a multidimensional commitment of the researcher in the ongoing considerations. What is more, it needs to be determined, in the first place, what rudimentary types of the researchers' involvement in the process of carrying out the research process are. Then, one should select the methods and techniques that fulfil the presented conditions;

- determining the size of the sample being researched - it is the last criterion, specified by the experts, which makes the availability of the given sample more precise. Assigned methods and techniques of conducting research processes are often dependent on the sample size (some of them are destined to assess smaller populations, whereas others are to evaluate bigger ones). 
Further on, the author presented his own (Dźwigoł, 2018) divisions of the components (modules) of the advocated research process, recommended by the experts (see the table below).

Table 1. Division of the components in the modules of selecting methods and techniques related to the research process

\begin{tabular}{|c|c|c|c|c|}
\hline Research subject & $\begin{array}{l}\text { Character of the } \\
\text { research studies }\end{array}$ & $\begin{array}{l}\text { Transparency of } \\
\text { the research goal }\end{array}$ & $\begin{array}{l}\text { Ways of conducting } \\
\text { the research studies }\end{array}$ & $\begin{array}{c}\text { Size of the } \\
\text { researched sample }\end{array}$ \\
\hline $\begin{array}{l}\text { - business entity, } \\
\text { - personal aspect, } \\
\text { - case (case study), } \\
\text { - phenomenon, } \\
\text { - environment, } \\
\text { - process. }\end{array}$ & $\begin{array}{l}\text { - } \text { identifying/ } \\
\text { explorative, } \\
\text { - } \text { secondary, } \\
\text { - experimental, } \\
\text { - diagnostical, } \\
\text { - model-related, } \\
\text { - } \text { analytical. }\end{array}$ & $\begin{array}{l}\text { - non-disguised, } \\
\text { - disguised. }\end{array}$ & $\begin{array}{l}\text { - indirectly, } \\
\text { - directly, } \\
\text { - participating, } \\
\text { - non-participating. }\end{array}$ & $\begin{array}{l}\text { - above } 20 \\
\text { observations, } \\
\text { - from } 20 \text { to } 50 \\
\text { observations, } \\
\text { - from } 50 \text { to } 100 \\
\text { observations, } \\
\text { - from } 100 \text { to } 250 \\
\text { observations, } \\
\text { - below } 250 \\
\text { observations. }\end{array}$ \\
\hline
\end{tabular}

Source: Own elaboration based on (Goleman, 1996).

Then, by means of the group expert assessment carried out with the use of the form, one was able to classify the selected methods and techniques within the framework of the adopted division of the modules of the elaborated procedure. The classification process involved five experts, i.e.:

- two practitioners carrying out the research studies within the scope of their basic managerial activities,

- two representatives of the management sciences,

- one statistician analysing data resulting from the carried-out research studies.

The survey form consisted of five parts corresponding to the subsequent modules of the research procedures (i.e. research subject, character of the carried-out research studies, transparency of the research goal, ways of conducting the research studies and size of the researched sample). Each of five parts of the survey was designed in the form of a matrix, containing: in the columns - methods ${ }^{3}(17)^{4}$ or techniques respectively ${ }^{5}(29)^{6}$, in the rows -

3 Methods: documentation analysis, survey, biographical survey, self-monitoring checklists, in-lab experiment, field (natural) experiment, expert group assessment, scenario-based method, observation, pseudoexperiment, psychography, other people's statements, projective tests, psychological tests, fitness tests, knowledge tests, interview.

4 Only the methods used in the basic research studies were subject to assessment and classification.

5 Techniques: analysis of non-formal clients' opinions, analysis of evaluation reports, analysis of staff meeting reports, any reports, memos and regulations, analysis of presented speeches and published interviews, standardised open question survey, anonymous mail survey, the Piorkowski apparatus (diagnosis of psychomotor skills), self-monitoring checklists as to professional qualifications and behaviours, graphology (personality assessment), introspective analysis of behaviours in critical situations, manipulation and inspection of environmental elements, undisguised observation of real events of critical importance, 
constituents of the procedure of selecting methods and techniques as to the research processes in the management sciences, which constituents had been identified earlier.

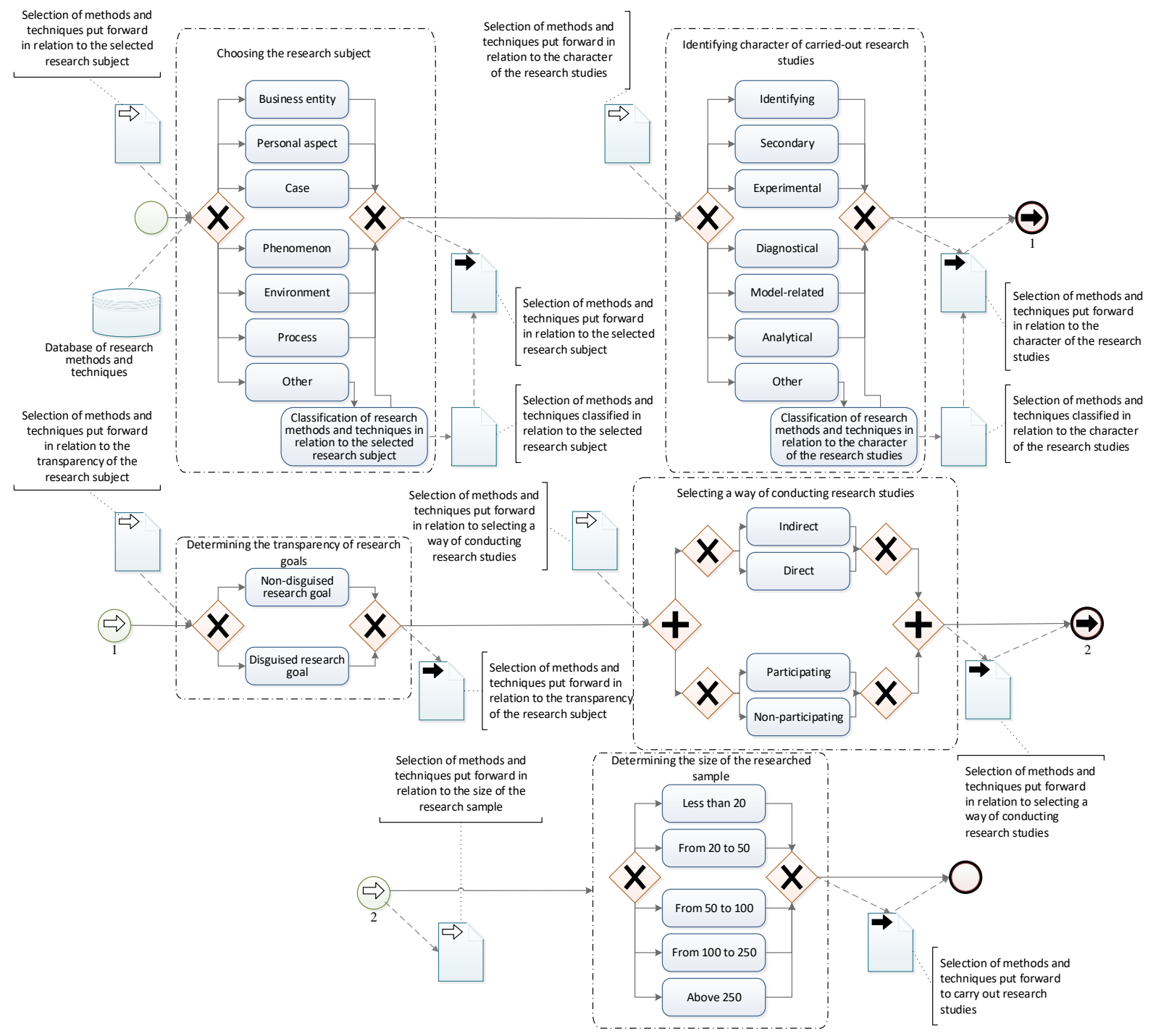

Figure 5. Procedure for selecting the methods and techniques within the managementrelated research processes

Source: the author's own work.

disguised and participant observations, disguised observation of induced stressful situations, observation standardised on the basis of rating scales, probation period at a given post, samples of task-related behaviours, rating scales to measure lifestyles, condition simulating (controlling and manipulating variables that determine a researched phenomenon), thematic apperception test (diagnosis of achievement motivation), vocational skills test, intellectual aptitude tests, temper tests, tests related to given areas of knowledge, structured free-form interview, weighted application form, situational interview (evaluating behaviours in a given situation), structured interview (repeated questions, prepared beforehand), focused group interview.

6 Only the techniques used in the main research studies were subject to assessment and classification. 
As a result of the conducted research study, one achieved a division of the research methods and techniques with regard to their subject, number, character, aim or a way in which the study is to be carried out.

The developed procedure of selecting the methods and techniques within the managementrelated research process consists of five phases that allow, in a considerable way, to answer any question which each researcher (both the academic and practitioner) should pose to himself/herself. What is more, the application of the developed procedure eliminates the need to diagnose research methods and techniques available in the literature through the use of the classification pattern, corresponding to five components of the procedure phases. Furthermore, it needs to be underlined that the selection of the research methods and techniques, with the use of the above-mentioned procedure, shall be followed by an analysis of posed theses, hypotheses or research questions, repeated from time to time. It means that the researcher should separately apply, for each posed hypothesis or research question, recommendations resulting from the developed procedure. It is explained by the diversity of the research problems in the management sciences (Dźwigoł, 2018).

The graphic representation of the described procedure has been created by means of the Business Process Model and Notation (BPMN). It is a graphic notation destined to describe business processes; it provides businesses with the opportunities to define and comprehend internal and external procedures by means of business process diagrams (Figure 5). Thus, it is possible to communicate on the basis of the adopted standards (Woodfield, 2018).

Phase I - selecting a research subject (Dźwigoł, 2018)

Selecting a research subject - the process involves designating a real research subject, determining its quantity (cases), features, components, as well as ways and possibilities of addressing it. In this phase the researcher selects a subject to be submitted to the research studies, which subject was earlier identified by means of an adopted model of the research methodology.

A starting point of the phase is a recommended classification of the research methods and techniques in terms of the research subject compliant with components of the phase:

- Business entity - all organisational units carrying out business activities for profitmaking purposes (within the scope of organisational structure). Within the said category, any business models, relations in organisational structures, etc. are taken into consideration.

- Personal aspect - staff (of various levels), behaviour patterns and organisational culture in the company. Within the scope of the category, staff's competences, their knowledge, progress in meeting organisational goals, etc. are put under scrutiny.

- Case study - a detailed case; within the scope of this category a real event is to be subject to analysis.

- Phenomenon (economic, social, etc.) - any events related to the business activity, the society; the events that affect the said entities. 
- Environment - nearer and farther environment, within the scope of this category broadly understood interested parties are taken into consideration - e.g. competitors, clients, suppliers and the society treated as an aggregate.

- Process (external, internal) - each act/action undertaken to achieve a determined effect. Within the category, internal and external processes, initiated by economic entities, are the subjects to analyses.

The basic process of the "selecting a research subject" phase involves a decision made by a researcher about classifying the research subject, thoroughly characterised earlier, into one of the recommended categories (module elements - phase). Should it be impossible to make such a classification, the researcher shall be obliged to assign, on his/her own, methods and techniques to categories which he/she had determined earlier. What is more, the researcher should, in the said case, make use of a questionnaire, containing selected earlier components of modules in the procedure of assigning methods and techniques to the research process within the scope of management sciences). The methods and techniques thus selected shall be treated as the author's own contribution to the above-mentioned procedure, and as a source of enriching benefits.

The starting point of the phase is a set of methods and techniques, gathered with regard to the selected research subject, as the latter shall be a point of departure in the next phase of the procedure execution. The cascade-like (step-by-step) execution of the procedure allows to eliminate the methods and techniques that fail to meet the coherence requirements as to all phases of the procedure.

Phase II - Determining the character of the carried-out research (Dźwigoł, 2018)

Determining the character of the carried-out research - it specifies the reason why researchers undertake to deal with a given research problem as contained in the analysis, hypothesis or research question being analysed. In this phase, the researcher chooses the character of the research goal.

- Character of the carried-out research - identifying - preliminary research studies, their aim is to identify a problem.

- Character of the carried-out research - secondary - the research studies involve an analysis of existing and widely available data, gathered earlier.

- Character of the carried-out research - experimental - the research studies involve searching for and verifying relations between two variables, with frequent variable manipulation.

- Character of the carried-out research - diagnostic - the research studies whose goal is to determine (diagnose) the condition of the given subject, its properties and operational principles.

- Character of the carried-out research - model - research studies whose goal is to reflect, in the best possible way, the researched subject by means of a selected model.

- Character of the carried-out research - analytical - observation-based research studies whose goal is to detect operational structures and mechanisms of the researched subject. 
The main process of the phase named Determining the character of the carried-out research is to make a decision by the researcher as to verifying the defined research goal, through determining its character by means of assigning it to the indicated module elements phases. Should the classification be unfeasible, the researcher shall be obliged, just like in the case of the previous phase, to assign by himself/herself the methods and techniques to the category determined on his/her own. To this end, the researcher should make use of a form, as described earlier, containing identified components of the procedure (modules) of selecting the methods and techniques within the management-related research processes.

Phase III - Determining the transparency of the research goal (Dźwigot, 2018)

The notion of transparency of the research goal undoubtedly plays an essential role as far as the selection of the research methods and techniques is concerned. The research methods and techniques, as described in the source literature, identify both the way in which the research process is performed and the research goal. In the present paper, the author adopted a widely used division of goal transparency, i.e. division between non-disguised and disguised goals. Then, the author classified methodologically the starting point of the phase, achieved in the previous phase, as a set of the research methods and techniques and an additional set of methods and techniques, classified as to the transparency of research goals.

- Research goal - non-disguised - the research subjects are aware of the goal of the research process in which they take part.

- Research goal - disguised - the research goal is known but only to the researcher.

The basic process of the phase named Determining the character of the carried-out research is for the researcher to make a decision as to the transparency of the defined research goal.

Phase IV - Choosing a way in which the research study is conducted (Dźwigoł, 2018)

Although a question of choosing a way of conducting research studies has been tackled in the source literature for many years, it still remains valid. There are two popular divisions. The first division presents the researcher's commitment in the research process as participating and non-participating one. The second division focuses directly on the way in which research studies are conducted, including direct and indirect ways.

- Ways in which research studies are conducted - indirect ones - the researcher is carrying out the research studies remotely, not participating personally in the study.

- Ways in which research studies are conducted - direct ones - the researcher is taking part in the study, participating actively in the whole research process.

- Ways in which research studies are conducted - participating ones - the researcher is taking part in the study, being "inside" the researched subject.

- Ways in which research studies are conducted - non-participating ones - the researcher is "outside" the researched subject, he/she does not interfere with the course of the research. 
The researcher's actions within the scope of the described phases involve selecting a way to carry out research studies with regard to the approach of the researcher himself/herself and his/her commitment.

Phase V - Determining the size of the sample being researched (Dźwigoł, 2018)

The last phase of the suggested procedure of selecting the methods and techniques suitable for the management-related research process involves determining the size of the sample being researched. The said phase, due to a wide variety of methods and techniques available, indicates more precisely those samples that are the most essential for the correct course of the research process. As a result of the undertaken research actions, five divisions were defined, each phase describing the constituent of the phase (i.e. less than 20; from 20 to 50; from 50 to 100; from 100 to 250; above 250).

- Size of the researched sample - less than 20.

- Size of the researched sample - from 20 to 50.

- Size of the researched sample - from 50 to 100

- Size of the researched sample - from 100 to 250.

- Size of the researched sample - above 250.

The effect of employing all constituents of the selection procedure covering methods and techniques is to achieve a suggested set of diagnosed and classified methods and techniques, as correlated to theses, hypotheses or research questions described by the author.

\section{Research conclusions}

The aim of the article was to present the elaborated procedure (Dźwigot, 2018) of selecting the methods and techniques for the sake of the management-related research process, as well as essential components of the research process used for designing the procedure in question. Since the research hypotheses were positively assessed, the author was able to present recommendations as to the putting the procedures into practice, which was supported by a dedicated online tool.

Research conclusion, as well as the analysis of domestic and foreign literature as to research methods and techniques in new management trends unequivocally prove that:

1. Having developed a research question, it is necessary to analyse selected quantitative and qualitative methods in order to make a preliminary selection.

2. Verification of elaborated methods, models or procedures is a prerequisite that allows to combine practical and theoretical aspects of management sciences.

3. Methodological triangulation supports research processes in management sciences.

4. Combining qualitative and quantitative methods in management-related research processes enhances the quality and reliability of research findings.

5. Expert groups assessment should be regarded as a basic method of evaluating trends of the carried-out research. 
The above-mentioned statements are confirmed by the research studies carried out by Bryman (Bryman, 2006, pp. 3-37); mixed research studies are widely applied in barely a few disciplines, whereas significant works are found mainly in American publications. While reviewing other research studies on the subject (e.g. by Niglas, 2004), one can draw a conclusion that mixed methods have been implemented relatively well in the management sciences, although the authors claim that their state is not satisfactory.

Furthermore, due to the research studies related to methods, procedures and approaches, it was found out which of these are the most essential for the research process and particular elements within the management sciences. It allows not only to determine the level of application of particular methods and techniques, or its amalgamation, but also identify certain rules of recognising the research process within the given context, as well as other variables that might affect the importance of assigning correct methods and techniques to a given research process, with the view of enhancing credibility, level and quality of the carried-out research studies. What is more, it is recommended to perform further research studies aimed at verifying the adopted model and procedure of selecting the research methods and techniques in the management sciences, and particularly in their practical aspect.

\section{References}

Ares, G., \& Varela, P. (Eds.). (2018a). Methods in Consumer Research, Volume 1: New Approaches to Classic Methods. Duxford, UK: Woodhead Publishing, Elsevier.

Ares, G., \& Varela, P. (Eds.) (2018b). Methods in Consumer Research, Volume 2: Alternative Approaches and Special Applications. Duxford, UK: Woodhead Publishing, Elsevier.

Boland, A., Cherry, G., \& Dickson, R. (Eds.). (2017). Doing a Systematic Review: A Student's Guide. London: Sage.

Bryman, A. (2006). Integrating quantitative and qualitative research: How is it done? Qualitative Research, 6(1), 3-37.

Coghlan, D., \& Shani, A.B. (Eds.) (2016). Action Research in Business and Management (Fundamentals of Applied Research). London: Sage.

Collins, H. (2010). Creative research. The theory and practice of research for the creative industries. Lausanne, Switzerland: AVA Publishing SA.

Denzin, N. (1970). The Research Act: Theorethical Introduction to Sociological Methods. Chicago: Aldine.

Dźwigoł, H. (2018). Współczesne procesy badawcze w naukach o zarzqdzaniu. Uwarunkowania metodyczne i metodologiczne. Warszawa: PWN.

Dźwigoł, H., \& Dźwigoł-Barosz, M. (2018). Scientific research methodology in management sciences.

Financial and Credit Activity: Problems of Theory and Practice, 2(25), 424-437. https://doi.org/10.18371/fcaptp.v2i25.136508 
Gerring, J. (2017). Case Study Research: Principles and Practices (Strategies for Social Inquiry). New York: Cambridge University Press.

Harrington, H.J., \& Voehl, F. (Eds.) (2016). The Innovation Tools Handbook, Volume 1: Organizational and Operational Tools, Methods, and Techniques that Every Innovator Must Know. Boca Raton FL, USA: CRC Press.

Hempoliński, M. (1992). Krytyka epistemologii fundamentalistycznej: R. Rorty i W.V.O. Quine. In J. Niżnik (Ed.), Pogranicza epistemologii. Warszawa: IFiS PAN [in Polish].

Kukuła, K. (2007). Elementy statystyki w zadaniach [Elements of statistics in tasks]. Warszawa: PWN [in Polish].

Labarca, C. (2017). Qualitative Research for beginners. Maracaibo, Venezuela: University of Zulia.

Mooi, E., Sarstedt, M., \& Mooi-Reci, I. (2018). Market research. The process, data, and methods using stata. Singapore: Springer Nature.

Niglas, K. (2004). The Combined Use of Qualitative and Quantitative Methods in Educational Research. Tallinn, Estonia: Tallinn Pedagogical University Dissertation on Social Science.

O'Leary, Z. (2017). The Essential Guide to Doing Your Research Project. London: Sage.

O'Leary, Z., Hunt, J.S. (2016). Workplace Research: Conducting small-scale research in organizations. London: Sage.

Pająk, K. (2010). Rozwój lokalny jako kategoria ekonomiczna [Local development as an economic category]. In A. Grzelak, K. Pająk (Eds.), Nowe trendy w metodologii nauk ekonomicznych [New trends in the methodology of economic sciences] (pp. 185-215). Poznań: Wydawnictwo Uniwersytetu Ekonomicznego [in Polish].

Petrova, V.M. (Ed.). (2018). Advances in Engineering Research. New York: Nova Science Pub Inc.

Quian, D. (2018). Adaptive Control: Methods, Applications and Research. New York: Nova Science Publishers Inc.

Quinton, S., \& Reynolds, N. (2018). Understanding Research in the Digital Age. London: Sage.

Robbins, D. (2009). Understanding research methods. A guide for the public and nonprofit manager. Boca Raton, USA: CRC Press, Taylor \& Francis Group.

Singleton, R.A., \& Straits, B.C. (2017). Approaches to Social Research. England: Oxford University Press.

Sloan, L., \& Quan-Haase, A. (Eds.) (2017). The SAGE Handbook of Social Media Research Methods. London: Sage.

Thomas, G. (2017). How to Do Your Research Project: A Guide for Students. London: Sage.

Woodfield, K. (Ed.). (2018). The Ethics of Online Research (Advances in Research Ethics and Integrity). Bingley, UK: Emerald Publishing Limited. 